\title{
Socialização e cultura escolar no Brasil
}

FRANCICLEO CASTRO RAMOS

Universidade Federal do Rio de Janeiro, Rio de Janeiro, RJ, Brasil

RESUMO

O artigo faz uma reflexão sobre a ampliação da escola para as classes populares no Brasil com o objetivo de responder às perguntas sobre os aspectos institucionais da escola pública brasileira e sobre sua capacidade de ensinar e educar para uma sociedade democrática: Qual tem sido o sentido da escola pública brasileira? Ela tem criado um ambiente capaz de ensinar e educar para uma sociedade democrática? Após destacar o papel do Estado no processo de afirmação da socialização escolar e na tarefa de realizar reformas sociais importantes e, posteriormente, apontar as mudanças na natureza da escola, o artigo conclui que o lento processo de democratização do ensino e a fragilização pela qual passou a sua constituição se revelam mais assustadoramente perigosos na possibilidade de não conseguir criar uma cultura escolar que estabeleça condições adequadas para valorizar as características individuais e sociais dos alunos na aprendizagem.

PALAVRAS-CHAVE

socialização escolar; cultura escolar; classes populares. 


\section{SCHOOL CULTURE AND SOCIALIZATION IN BRAZIL}

\section{ABSTRACT}

The article reflects on the school expansion for the popular segment in Brazil in order to answer the questions about institutional aspects on Brazilian public schools and their capability to teach and educate a democratic society: what has been the direction of the Brazilian public school? Has it has been creating an environment able to teach and educate a democratic society? After highlighting the State's role in the process of affirming school socialization and in the task of accomplishing important social reforms, posteriorly pointing out changes in the functions of the school, the article concludes that the slow process of democratization of education and the weakening undergone by their constitution revealed the possibility of failing to create a school culture that establishes conditions for valuing individual and social characteristics of students in learning.

\section{KEYWORDS}

school socialization; school culture; low income students.

\section{SOCIALIZACIÓN Y CULTURA ESCOLAR EN BRASIL}

\section{RESUMEN}

El artículo reflexiona sobre la expansión de la escuela para las clases populares en Brasil con el objetivo de responder a las preguntas sobre los aspectos institucionales de la educación pública brasileña y su capacidad de enseñar y educar una sociedad democrática: ¿cuál ha sido el sentido de la escuela pública brasileña? ¿Se ha creado un ambiente capaz de enseñar y educar una sociedad democrática? Después de destacar el papel de Estado en el proceso de afirmación de la socialización escolar y en la tarea de conducir reformas sociales importantes y, posteriormente, señalar los cambios en la función de la escuela, el artículo concluye que el lento proceso de democratización de la educación y el debilitamiento sufrido por su institución aparece más terriblemente peligroso en la posibilidad de no poder crear una cultura escolar que establece las condiciones para la valoración de las características individuales y sociales de los estudiantes en el aprendizaje.

PALABRAS CLAVE

socialización escolar; cultura escolar; clases populares. 


\section{INTRODUÇÃO ${ }^{1}$}

Socialização e cultura escolar são conceitos complementares e ajudam-nos a compreender as práticas educativas e o processo desenvolvido, segundo o qual se afirma a existência de uma forma institucional específica. Ambos os conceitos permitem que o investigador se debruce sobre as questões escolares (por exemplo, indisciplina, desempenho e rendimento) e as implicações da escola na vida dos indivíduos, assim como servem de ponto de partida para questionar o papel das instituições de ensino e a própria relação entre escola e sociedade. Se quisermos marcar uma diferença entre essas duas noções, podemos dizer o seguinte: enquanto a cultura escolar pode ser utilizada para acessar um jogo de tensão entre as diferentes matrizes de culturas - que naturalmente desafiam a escola, especialmente se o trabalho pedagógico adotar a perspectiva que frisa ser importante considerar os contextos culturais dos alunos, mas sem cair no extremo do relativismo - a socialização é uma chave de entendimento da complexa interação entre as afirmações individuais dos alunos que remetem às suas culturas de origem e à prática institucional que orienta o processo de ensino-aprendizagem, sendo esse a ocorrer segundo os valores mais amplamente difundidos de uma determinada sociedade.

Talvez esses conceitos assumam formas privilegiadas para a investigação sociológica da nossa instituição escolar, que se fixou de uma tal maneira, cuja principal marca é a necessidade de mudanças que estejam comprometidas com a finalidade de criar conexões mais equitativas com as classes populares. Isso porque, se há complexidade remetida ao público que a escola atende, principalmente referida aos baixos indicadores socioeconômicos das famílias, há também quanto às expectativas da própria escola em relação a ele. Essa via de mão dupla, na realidade, revela tensões próprias de um particular espaço-tempo, o escolar, mas ganha contornos mais excludentes no contexto de uma sociedade que tardiamente se desafiou a massificar a escolarização. Não à toa, o saldo contemporâneo da questão educacional brasileira é o de um enorme déficit, menos de acesso, mas sobretudo de qualidade.

A escola enfrenta dificuldades colocadas pela missão constitucional de difundir conhecimentos e saberes para a cidadania e para o trabalho. Não é que esteja em crise, sintoma que motiva sua quase destruição. Ao contrário, está vivendo um momento oportuno para ajudar a redefinir os termos da relação com as classes populares, público historicamente excluído dos capitais mais promotores de bem-estar social. Nesse sentido, faz-se necessário dizer que a escola tem uma missão muito clara: contribuir para a construção dos papéis sociais fundamentais ao projeto de democracia, o que pressupõe considerar como horizonte a equidade escolar.

Com efeito, como se trata de um horizonte, uma pergunta faz-se importante: Como tornar o processo de socialização desenvolvido na/pela escola em uma prática concreta para a equidade social? Tomar essa questão como um pano de fundo mais amplo parece cumprir bem o papel de problematizar a relação escola e sociedade

1 Agradeço enormemente a revisão textual de Camila de Souza Ferreira. 
estabelecida na nossa ordem social, bem como ajuda a iluminar os dilemas escolares que estão por trás da dinâmica da socialização escolar brasileira.

Então, seguindo esse raciocínio, algumas perguntas são indispensáveis acerca dessa nossa proposição: Quais os termos da nossa expansão escolar ou o que configura o movimento de expansão da escola no Brasil? E qual tem sido o sentido da escola brasileira? Ela tem conseguido um ambiente para ensinar e educar? Essas questões servirão de inspiração para tratarmos do processo de expansão da oferta do ensino público obrigatório, bem como para analisarmos a complexidade inerente à relação entre a escola e o segmento popular. Isso nos permite problematizar a construção de uma cultura escolar democrática. Em termos mais curtos, em primeiro lugar, a ideia é explorar o movimento de afirmação da escola para as classes populares e, posteriormente, pensar as mudanças institucionais em suas contradições e tensões, que são reveladoras da seletividade interna e dos obstáculos a uma interação mais rica com os estudantes.

\section{A LENTA DEMOCRATIZAÇÃO DA SOCIALIZAÇÃO ESCOLAR NO BRASIL}

Organizar o quadro sobre a expansão da escolarização realizada no Brasil é certamente uma construção que exige, desde o início, considerar a existência de diversas formas de encarar a questão. O objetivo aqui consiste em mobilizar algumas análises acerca da constituição e de sua afirmação enquanto instituição socializadora das classes populares.

A ampliação da escola - movimento que pode ser entendido como fruto da forte insistência de parte de alguns intelectuais, com uma parcela específica da sociedade, em defender a existência de certa igualdade como um direito social, desnaturalizando, dessa forma, um imaginário típico de terras de privilégios - ${ }^{2}$ traz consigo um profundo debate em que as marcas da contradição, da tensão e dos conflitos político-ideológicos materializam o penoso desafio das classes populares de ter o direito de estudar garantido. Esse movimento de expansão da escola, apesar de ter sido impulsionado pela ideia de modernização democrática da sociedade, não chegou a ser realizado tão facilmente, porque havia um conjunto de perspectivas bastante divergentes, retardando intervenções que pudessem modificar a configuração de exclusão social no país. Mas a partir de que momento da história essa realidade de exclusão passou a ser efetivamente combatida? Em que condições a escolarização passa a fazer parte do mundo popular?

2 Essa ilustração do privilégio como importante presença na sociedade brasileira é mais bem localizada nas relações pessoalizadas que buscam suspender o ritual cuja igualdade é tida como a unidade básica da socialidade. Roberto DaMatta (1997) mobiliza o "sabe com quem está falando" para destacar os pormenores dessa questão no nosso universo social. Do ponto de vista histórico, não esqueçamos as manobras de "inserção" dos negros com o fim da escravidão, cuja forma privilegiou a permanência da estrutura de poder assimétrica da relação racial entre brancos e negros, na realidade uma "inserção" que configura uma negação da igualdade. 
Uma parte das análises que tratam da ampliação da oferta escolar mostra que as classes populares, em sua diversidade de pobreza e etnia, vivenciaram um lento processo de democratização do ensino ao longo do século XX. A década de 1920 parece ser um importante ponto de partida, pois é nesse período que emerge a primeira proposta de universalização da alfabetização para todas as crianças em idade escolar. ${ }^{3} \mathrm{Na}$ década de 1920 , ocorreu um conjunto de reformas educacionais nos estados que não conseguiu modificar o quadro de exclusão do ensino. A reforma encabeçada por Sampaio Dória no estado de São de Paulo, por exemplo, apesar de procurar instituir uma escola primária, cuja primeira etapa com a duração de dois anos seria gratuita e obrigatória para todos (Saviani, 2004), nunca chegou a ser uma realidade naquele estado.

O esforço dessa reforma foi uma tentativa de proporcionar um direito básico aos excluídos, mas a questão ganha destaque somente na década de 1930, anos em que intelectuais como Anísio Teixeira e Fernando de Azevedo lançam um documento que em sua reflexão articula o crescimento social brasileiro à oferta obrigatória de ensino público gratuito a todos. Esse documento ficou conhecido como Manifesto dos Pioneiros da Educação de 1932.

O Manifesto de 1932 é uma importante contribuição à compreensão da condição educacional brasileira naquele contexto dos quarenta e três anos de regime republicano e, particularmente, uma boa forma de pensar a situação das classes populares nessa realidade. Entre as principais causas da precária condição educacional estavam a fragmentação e a desarticulação das reformas programadas, bem como o fato de serem precisamente parciais e arbitrárias a ponto de não conseguiram reagir à crítica situação escolar. Enquanto isso, uma importante camada social esperava ter acesso à escola e participar do processo de modernização. Na realidade, uma dimensão política estava claramente colocada. Aliás, qual seriam os objetivos da escola? A que as suas finalidades estariam a serviço? O Manifesto de 1932 não deixou de fazer a crítica às ações que demarcavam uma evidente relação entre escola e meio social, isto é, ações que vislumbravam uma escola fundada na divisão de classes, e não na formação do sujeito.

De modo sintético, o Manifesto dos Pioneiros apresenta uma proposta que consiste na afirmação da educação escolar enquanto ação legitimadora não dos interesses de classes, como enfatiza o exercício de sua função até então, mas do reconhecimento do direito de todo indivíduo de ser escolarizado até onde o permitirem as suas aptidões naturais, independente de razões de ordem econômica e social. Uma das premissas da moderna instituição escolar é agir em defesa do princípio da equidade social, em que a diferenciação entre os indivíduos configura-se como

3 Dermeval Saviani (2004, p. 2), em O legado educacional do século XX no Brasil, afirma que as transformações mais relevantes da sociedade brasileira nos âmbitos econômico, político, cultural e, inclusive, educacional estão localizadas duas décadas antes da virada para o século XX, ou seja, em 1880. No entanto, o pesquisador reconhece que o marco da questão educacional para as massas é a década 1920, já o período de 1931 a 1961 caracteriza a "regulamentação, em âmbito nacional, das escolas superiores, secundárias e primárias, incorporando crescentemente o ideário pedagógico renovador”. 
resultado de uma dinâmica que se desenvolve para além da dimensão econômica. No trecho a seguir, esse ponto é denominado de hierarquia democrática.

A educação nova, alargando sua finalidade para além dos limites das classes, assume, com uma feição mais humana, sua verdadeira função social, preparando-se para formar "a hierarquia democrática" pela "hierarquia das capacidades", recrutadas em todos os grupos sociais, a que se abrem as mesmas oportunidades de educação. Ela tem, por objeto, organizar e desenvolver os meios de ação durável, com o fim de "dirigir o desenvolvimento natural e integral do ser humano em cada uma das etapas de seu crescimento", de acordo com uma certa concepção do mundo. (Azevedo, 1932, p. 40)

Era a defesa de uma democracia republicana no Brasil pela elite intelectual modernista. A proposta era a de diminuir as restrições de acesso aos direitos sociais e fortalecer o caminho para a afirmação de uma realidade de menor exclusão social. A partir de então, evidentemente considerando o debate que ocorria desde os anos de 1920, começou a ganhar folêgo a ideia de uma escola que atendesse e garantisse uma formação básica comum a todos. No entanto, a sua realização não aconteceu imediatamente, uma vez que passou por um processo de profundo conflito de interesses que desenhou os traços gerais de uma expansão escolar à brasileira.

A educação escolar tornou-se um campo de disputa ideológica, política e religiosa entre os partidários da Escola Nova e intelectuais de ensino de perspectiva católica e militar. $\mathrm{O}$ fato é que estava em debate distintas concepções sobre o papel da escola e de que maneira a educação escolar chegaria às classes populares. A concepção escolanovista, filiação dos intelectuais do Manifesto, defendia uma reforma democrática da escola pública, ao passo que a Igreja católica, cuja concepção educacional baseava-se na filosofia cristã e totalmente segmentária, reagia a fim de garantir a sua predominância na oferta de formação escolar e o poder de influênciar culturalmente a sociedade brasileira. Essas concepções refletiram na construção do Plano Nacional de Educação enviado para aprovação do Congresso em $1937 .{ }^{4}$

Em resumo, as substâncias dessa discussão condensam a defesa da Igreja católica pela total liberdade de ensino e autonomia das escolas, porque, de um lado, não queria perder o monopólio nesse campo para o Estado e, de outro, acreditava em uma escola com formatos diferenciados segundo a classe social. Então, na concepção da Igreja, implantar a "escola única" proposta pelo Manifesto de 1932 seria uma real "tentativa de emburguesamento do operariado" (Schwartman, Bomeny e Costa, 2000, p. 194). A Igreja argumentava que as condições operárias exigiam apenas cursos secundários e paralelos à atividade produtiva, e isso não entraria em

4 Schwartzman, Bomeny e Costa (2000) mostram que, à frente do Ministério da Educação, em 1936, Gustavo Capanema organizou um questionário com perguntas sobre princípios, finalidades, sentidos, organização, burocracia, conteúdo, metodologia, entre outras questões, e enviou para diferentes setores organizados da sociedade brasileira (intelectuais, Igreja e corporação militar), com o objetivo de reunir as mais diversificadas posições que dariam lugar à formulação do Plano Nacional de Educação. 
conflito com as próprias competências das classes populares. Além disso, também seria necessário evitar o desenvolvimento de valores, como o individualismo e as concepções socialistas que prejudicariam e colocariam em xeque as bases do valor à família. Portanto, conforme Schwartzman, Bomeny e Costa (2000, p. 194), enquanto a Escola Nova "via na educação um instrumento de neutralização das desigualdades sociais, a Igreja percebia-na como tendo por finalidade a adaptação dos desiguais a uma ordem social naturalmente hierárquica”.

É bom dizer que, no processo de modernização social, a escolarização torna-se peça fundamental, ou melhor, um capital de poder cuja disputa ocorre na política pelas alianças erguidas na Revolução de 1930. Essa aliança vai perdurar no Estado, que assume papel de conciliador dos interesses das diferentes frações de classes. Nesse sentido, particularmente em matéria de expansão da escola, o Estado postulou uma governabilidade que efetivamente empurrou com a barriga o lento avanço na afirmação da escolaridade na vida das pessoas com escassas condições de acesso ao ensino.

Isso fica claro nos marcos dos decretos educacionais, como a Lei Orgânica do Ensino Primário de janeiro de 1946, na qual está presente que, embora o ensino primário elementar (com quatro anos de duração) fosse definido como obrigatório (para a faixa etária de 7 a 12 anos), a tarefa de ofertar escola "era fundamentalmente definida como responsabilidade civil” (Algebaile, 2009, p. 103), e não do Estado. Ao transferir essa responsabilidade para a sociedade civil, o Estado abre margem para a reprodução de um modelo escolar que expressa profunda desigualdade no seio da vida social. Na realidade, o Estado mostra-se ao mesmo tempo incapaz de ser o portador do projeto de democratizar a escola e retarda o provimento da educação como um direito social.

Disso podemos frisar duas conclusões: primeiro, com a oferta sendo insuficiente, o acesso era escasso, mas também os impedimentos criados pela sociedade foram fatores preponderantes (Algebaile, 2009). Esses impedimentos são aqueles forjados no processo de transferência da responsabilidade de ofertar a escola. Por exemplo, construir uma escola em propriedade privada certamente não era uma tarefa fácil. Segundo, da incapacidade do Estado e da transferência para os grupos com poder local, configura-se um modelo de aquisição dos direitos sob a marca das relações políticas.

O desafio educacional era imenso, mas um direito social estava posto em discussão na agenda pública. Contudo, não se tratava de algo que foi conquistado com certa regularidade. Algebaile (2009) enfatiza bem esse ponto ao analisar as constituições de 1934 e 1937: enquanto a Constituição de $1934^{5}$ estabelece maior detalhamento nas obrigações orçamentárias para subsidiar a oferta educacional entre as unidades de governo, a de 1937 dilui essas obrigações. Isto é, a primeira constituição avança em determinar as disposições sobre o financiamento educacional, enquanto a segunda, do Estado Novo, atribui obrigações secundárias ao Estado, principalmente no que diz respeito à matéria orçamentária do ensino obrigatório. Sem investimento não há sequer o desenho da política pública.

5 A primeira definição legal da educação como um "direito de todos, que devia ser proporcionado 'pela família e pelos poderes públicos”, foi na Constituição de 1934 (Algebiale, 2009, p. 99). 
Assim, além de o direito à escola ter sido afirmado lentamente, pode-se dizer que também se revelou oscilante. Esse é um dado que de uma ou de outra maneira ajuda a entender o quão frágil é a nossa escola pública. É que a garantia jurídica do direito social, cuja afirmação também depende da pressão do setor da sociedade mais prejudicado, define em que medida o Estado deve atuar para salvaguardar as finalidades expressas na lei. A identifcação dos retrocessos e avanços constitucionais é uma boa régua para medirmos o grau de abertura que uma sociedade preza para efeitos de mobilidade e bem-estar de determinados grupos sociais, mas também o próprio compromisso do Estado em atender a isso.

Um passo importante com vistas à concretização do direito à educação escolar foi dado na Constituição de 1946 que, ao contrário das outras, explicitou que "o ensino primário oficial é gratuito para todos", sendo a retomada da descrição de percentuais referentes às responsabilidades orçamentárias das unidades de governo uma importante disposição para a sua realização. Essa regulação dos percentuais mínimos de investimento foi reiterada na Lei de Diretrizes e Bases da Educação (LDB) de 1961, que até mesmo inovou ao forjar as alíneas "manutenção e desenvolvimento do ensino" "despesas com o ensino" como conceituações da aplicação financeira na área (Algebaile, 2009, p. 104). Essas mudanças na LDB de 1961, porém, falam apenas da providência do Estado em relação aos encargos educacionais. A responsabilidade com a educação obrigatória ainda consta como dever principalmente da família, e a efetiva atuação do Estado configura-se como minimalista, pois "inúmeros mecanismos da regulação da oferta se mantiveram imprecisos ou abriram brechas para a não efetivação da ampliação do número de vagas públicas como prioridade (Algebaile, 2009, p. 106).

A ausência ou a existência de imprecisões normativas não deixam de ser uma representação de como a elite política conteve uma etapa importante do processo de modernização da sociedade. A lenta expansão dos direitos sociais e a maneira como o Estado agiu com a obrigatoriedade escolar fazem entender que houve atenuação da concepção pública do sentido de dever que teria de presidir a atuação desse ente (Algebaile, 2009) cuja postura também instalou inúmeras restrições ao direito à educação para a classe popular brasileira.

O Estado assume uma obrigação mais precisa na Constituição Federal de 1988 e, posteriormente, em 1996, com a nova LDB. Na Constituição Federal de 1988, o ensino obrigatório e gratuito trata-se de um "direito público subjetivo" e a não realização desse dispositivo legal, ou sua realização insuficiente, consiste em infração e gera punições à autoridade competente. Quanto à LDB de 1996, há a ratificação desse direito público subjetivo e formas de responsabilização do poder público que não assegurar o direito social à educação.

A expansão da oferta escolar em todo o território somente se realiza quando o Estado ${ }^{6}$ assume efetivamente essa responsabilidade. Obviamente que isso não aconteceu sem a pressão de alguns setores sociais, como o clamor de alguns inte-

6 No caso, como é possível encontrar nos Manifestos de 32 e 59, não se trata de "centralismo", mas de uma ação conjugada da federação a fim de assumir o papel na garantia do direito social à educação. Isto é, o Estado não deixa à iniciativa privada a responsabilidade de ofertar e garantir esse direito, ao contrário, torna-se ator principal do processo. 
lectuais e de movimentos sociais com suas lutas pela educação popular nas décadas de 1950 e 1960 e, mais à frente, de organismos internacionais que representam fielmente o movimento da "difusão mundial da escola" (Nóva e Schriewer, 2000). Não esqueçamos que, assim como aconteceu em 1932 por iniciativa dos Pioneiros da Educação Nova, em 1959, pensadores da educação lançaram um manifesto intitulado "Mais um vez convocados: manifesto ao povo e ao governo", redigido por Fernando de Azevedo para reafirmar, nos anos que antecederam a aprovação da LDB de $1961,{ }^{7}$ a importância da ampliação, do ensino público pelo Estado. Vale lembrar que, historicamente, esse processo tem sido construído lentamente, "peça por peça, através de dificuldades imensas" (Azevedo, 2010, p. 88).

É bom registrar que o Manifesto de 1959 argumenta a favor da expansão escolar no contexto do pós-guerra, em que, pelo menos até 1970, a social-democracia europeia enfatizava a responsabilidade do Estado em ampliar sua capacidade de atendimento com vistas a promover mais justiça social. Aqui, no Brasil, pela democracia liberal, o referido Manifesto, apesar de não falar em justiça social, expressa nuances que correspondem a esse princípio, tal como podemos verificar na seguinte passagem: "que o país pelos seus órgãos competentes não tenha cumprido os seus deveres para com as novas gerações, sistematicamente esquecidas e entregues, em grande parte, à sua própria sorte, não há sombra de dúvida. Os fatos aí estão para atestá-lo com uma evidência agressiva" (Azevedo, 2010, p. 75).

Não custa lembrar que o Manifesto de 1959 defende a escola pública por ser uma conquista consagrada em outras nações, processo que o Brasil não pode ignorar. Logo, os autores ressaltam que ao Estado compete promover a educação escolar de modo que possa difundir e fortalecer os princípios e as instituições democráticas, bem como produzir a sua riqueza pelos termos do progresso científico e tecnológico.

Então, e depois de resenhar algumas linhas básicas do processo de afirmação do direito escolar, podemos apresentar algumas conclusões. Uma primeira é que durante muito tempo a ampliação da escola para as classes populares não se revelou como uma questão social a ser solucionada pelo Estado. O sentido da escola como uma "questão social", usado aqui, refere-se à capacidade do Estado de gerenciar e solucionar os problemas gravitantes na sociedade. Esse ente revelou-se incapaz, talvez porque não estava no horizonte construir uma igualdade social a partir do acesso à educação escolar.

É somente no período de 1920-1930 que começam a ganhar notoriedade as possibilidades de a escola tornar-se a via pela qual o filho da classe popular deverá ser socializado. Mas, na verdade, esse período marca o início de uma luta que se desenvolve, basicamente, entre duas perspectivas diferentes da relação escola e sociedade: para uma, a escola deve ser compreendida como uma instituição que atenda à "vocação" da sociedade, isto é, se é uma sociedade de classe, a escola a legitima conferindo formação educacional correspondente, pois da estrutura de classe

7 A LDB de 1961 é, na verdade, segundo Algebaile (2009), resultante do projeto elaborado entre 1947 e 1948. Exatamente, a sua aprovação deu-se após apenas treze anos de intensos debates e numerosas emendas. 
deriva todo o sistema social - essa perspectiva pode ser vista na defesa da Igreja em preservar a liberdade de ensino; para outra, a escola é vista como uma instituição republicana que deve educar as classes populares para a dinâmica da sociedade capitalista e inserção no regime democrático.

Uma segunda conclusão é a de que o movimento da expansão da educação escolar ocorre concomitante à implantação do processo de industrialização e de construção do nacionalismo. "Essa bandeira da industrialização aglutina um conjunto grande de forças que vão desde a incipiente burguesia nacional passando pela burguesia internacional e as camadas médias até as forças de esquerda" (Saviani, 1991, p. 64), de modo que em campos importantes, como o educacional, apesar de ter ganhado mais visibilidade, persiste a incorporação dos interesses das forças de pressão, as quais não modificaram questões de base, como o caráter segregador da educação. Em outras palavras, ao aglutinar os interesses dos diferentes grupos, o Estado incorporou demandas que retardaram reformas promotoras de uma nova dinâmica da relação entre as classes sociais no Brasil.

E outra, uma terceira conclusão decorrente da primeira é que, ao demorar a considerar que a expansão escolar fosse uma questão social, o Estado, visando à industrialização e à nacionalização, agiu como um agente disposto a ofertar apenas o mínimo. A noção mínimo, como nos diz Algebaile (2009, p. 95), é substancialmente diferente da noção básico: enquanto a primeira faz referência a limites ínfimos de satisfação, a segunda é uma noção "que serve de base de sustentação indispensável e fecunda ao que a ela se acrescenta". Nesse sentido, não por acaso existem imprecisões nas regulamentações e fragmentação nas ações da ampliação da escola.

Diante disso, entende-se que a questão da democratização do ensino tem uma trajetória complexa e longe de ser algo tão recente. Na realidade, perpassa quase todo o século XX, mas efetivamente só ganha força quando entendida como uma instituição fundamental para a construção da sociedade democrática. É, então, no período entre 1960 e 1980, especialmente sob a articulação escola/democracia proveniente das reinvidicações por mais abertura política e ampliação de direitos, que a instituição escolar assume crescente protagonismo na socialização das crianças e adolescentes do mundo popular. ${ }^{8}$

A mudança impulsionada pela perspectiva democrática, a despeito de ter ocorrido de forma lenta e fragmentária no nosso país e de também ter trazido elementos de certos momentos autoritários, está diretamente relacionada ao acesso à escola, à difusão da socialização escolar a todos o indivíduos. Mas pressionar a

8 Vale registrar que em 1964 o percentual de escolarização para a população de 7 a 14 anos, no Brasil, era de 66,28\%. Isso significa que, em todo o território nacional, 33,72\% das crianças dessa faixa etária ainda permaneciam fora da escola (Romanelli, 1984, p. 82). A década de 1980 caminha de forma mais intensiva e, no início dos anos de 1990, especificamente em 1992, a referida taxa subiu para 86,59\% e 88,6\% em 1993. A evolução da taxa de escolarização para a faixa etária de 7 a 14 anos, no período 1995 a 2007, foi a seguinte: 90,22\% (1995); 91,26\% (1996); 92,99\% (1997); 94,7\% (1998); 95,69\% (1999); 96,46\% (2001); 96,94\% (2002); 97,19\% (2003); 97,19\% (2004); 97,43 (2005); 97,73\% (2006); 97,67\% (2007) (IBGE, Pesquisa Nacional por Amostra de Domicílios 1992/2007). 
abertura dessa instituição é colocar em pauta a capacidade de integrar as classes populares em torno de um projeto de bem-estar social, uma régua republicana que recusa a permanência desse segmento nos mais baixos indicadores sociais. A expansão do capital escolar é uma das principais marcas de democracias consolidadas e de sociedades capitalistas mais equitativas. Contudo, realizar a premissa de democratizar o conhecimento promovido pela escola não é uma tarefa simples. Um dos primeiros passos a ser perseguido consiste em fortalecer a escola e, ao mesmo tempo, sensibilizá-la para estabelecer canais de comunicação mais simétricos com seu público (estudante e sua família). Não há como promover essas mudanças sem intervir na forma cultural que define a atuação da escola. O que está em jogo é o enorme desafio de criar uma cultura escolar que saiba lidar com a desigualdade e a diversidade que permeiam as relações nos processos pedagógicos.

\section{AS QUALIDADES DE SUA EXPANSÃO: A DIFÍCIL CONSTRUÇÃO DE UMA CULTURA ESCOLAR DEMOCRÁTICA}

A breve resenha do processo de expansão da escola, na qual procuramos enfatizar alguns pontos acerca de suas características, fala de uma redefinição da relação entre escola e sociedade no decorrer do século XX, principalmente no que diz respeito à condição das classes populares que, progressivamente, foram incorporadas ao ensino. Isso é um reflexo da ampliação dos direitos sociais no Brasil. Entretanto, o direito à educação foi formalmente marcado pelo estabelecimento de "mínimos" e ofertado de maneira seletiva e desigual, tanto que medidas e leis registravam dois tipos de escola: uma profissionalizante, para pobres, e outra de caráter mais amplo, digamos, intelectualista, para ricos. Com o caminhar em direção à afirmação da democracia, muito embora em meio a regimes autoritários e centralizadores no percurso, a escola, em detrimento da família e também do trabalho, passou a ser convocada a assumir o lugar de agência fundamental para a socialização da ampla população.

A entrada da classe popular na escola, a chamada massificação escolar, produziu profundas mudanças na natureza dessa instituição e, consequentemente, na qualidade de seu trabalho. ${ }^{9} \mathrm{O}$ resultado mais preocupante disso, do ponto de vista sociológico, é que o acesso à escola tem configurado a emergência de novas precariedades na sociedade brasileira. $\mathrm{E}$ isso, de alguma maneira, representa a difícil tarefa de produzir a equidade social no Brasil. Isto é, a realização efetiva de um projeto igualitário de oportunidades na nossa ordem social dificilmente ganha maior envergadura. Talvez o processo de escolarização ofertado às classes populares, ao qual creditamos muitas expectativas, possa ser o motor preponderante desse projeto, mas o vigor de sua força não pode vir acompanhado de circuitos que representam formas de marginalização e distinção. É claro que a marginalização institucional da

9 Vale lembrar que a massificação escolar de que se fala é o processo de abertura da escola para uma camada antes desassistida do direito à educação escolar, que ganha contornos de maior alcance a partir da década de 1960. 
escola já ganhou vida, basta lembrarmos da segregação à qual foi submetida com a progressiva evasão da classe média assim que ocorreu a abertura de suas portas para o mundo popular, mas também pelo efeito "fuga" de certos setores populares que aderiram à ideologia da escola privada — só que diferentemente da escola daquela, a dos populares permanece no espaço social periférico.

Esta seção pretende discutir algumas mudanças que revelam as novas características da escola, as quais emergiram com o processo de massificação e que demonstram um processo de fragilização dessa instituição social. Enfatiza-se, em particular, que um dos efeitos dessas mudanças refere-se à forma de a escola se relacionar com o seu público, o que, pode-se dizer, remete à complexa condição social de seus alunos, aos efeitos da segregação urbana e à própria tensão que permeia a relação da escola com as famílias.

Ao localizar a escola pública brasileira no conjunto das instituições que fazem parte da reprodução do capitalismo contemporâneo, que por sua vez engendra novas (ou o aprofundamento) desigualdades diluídas no tempo, em especial no tempo escolar, Peregrino (2010) procura entender as formas de "recusa de escolarização" para crianças e jovens populares mesmo que a experiência escolar faça parte de suas vidas. Com base na formulação teórica de Bourdieu, a autora afirma que a "recusa" se dá no contexto das relações de produção do capital em que a escola tem sido um lugar de legitimação dos "excluídos em potenciais", principalmente pelo fato de ela ter perdido a finalidade de conferir um conhecimento capaz de formar sujeitos para disputarem igualmente o espaço social.

À escola vem cabendo, historicamente, legitimar as desigualdades constantemente postas por esse modo de produção, selecionando o acesso aos produtos materialmente e simbolicamente produzidos. Nesse sentido, a marca do nosso tempo tem relação com o fato de que "o processo de eliminação foi adiado e diluído no tempo: e isto faz com que a instituição seja habitada a longo prazo por excluídos em potenciais, vivendo as contradições e os conflitos associados a uma escolaridade sem outra finalidade que ela mesma”. (Bourdieu, 1998, p. 482-483 apud Peregrino, 2010, p. 61-62)

A exclusão social diluída no tempo é um fato concernente às sociedades capitalistas, cujas instituições e período escolar contribuem com a sua legitimação. Então, pode-se dizer que essa "recusa de escolarização" é uma das principais características das sociedades que reinstituem desigualdades valendo-se de um processo de inclusão fragilizada. Peregrino (2010, p. 76) enfatiza que a inserção periclitante de segmentos importantes da sociedade é especialmente revelada em um jogo que, de um lado, "possui múltiplas formas de inclusão precarizada no âmbito econômico" e, de outro, uma lógica "excludente do ponto de vista social, moral e político". Esse processo ganha conotações particulares no Brasil com a forma de expansão da escola à classe popular. É que a lenta e gradual oferta do "mínimo" (Algebaile, 2009) representa a reafirmação de privilégios (para poucos setores da sociedade), ou seja, mesmo com o alargamento dos direitos sociais à ampla maioria, quebrar a fronteira da desigualdade não é algo imediato. Com efeito, é com a "mutação" da 
função dessa instituição (Peregrino, 2010) que o peso dessa arquitetura mostra a sua dimensão mais refinada. Vamos à explicação.

No contexto da ditadura militar, o Estado, com base no modelo tecnocrata e de modernização autoritária, realizou a reforma do ensino universitáro (lei n. 5.540/1968) mais os ensinos de primeiro e segundo grau (lei n. 5.692/1971) — em que, de modo geral, estabelece os princípios de formação educacional para atender aos interesses da produção econômica e, de modo específico, a ampliação do ensino primário obrigatório de quatro para oito anos, a fim de reorientar o sistema educacional. Entretanto, o processo denominado de "liberação do ensino elementar" (extensão do ensino primário obrigatório) não consiste em uma efetiva incorporação dos contingentes recém-chegados à escola. A questão é que um conjunto de orientações para o mundo do trabalho ocupa o espaço escolar com "disciplinas como 'técnicas comerciais', 'artes industriais', 'educação para o lar", causando uma verdadeira restrição "às funções clássicas da ação escolar” em nível nacional (Peregrino, 2010, p. 90-91).

Essa ideologia de uma "escolarização orientada para a empregabilidade" proporciona menos mudanças na estrutura social que uma "ampliação das tarefas" da escola. Na realidade, exerce um deslocamento dos fins eminentemente educacionais que, a rigor, produz sérios prejuízos à integração social (Algebaile, 2009).

Para Peregrino (2010), essa política que confere novas funções à escola ganha contornos específicos de "gestão da pobreza", pois, nas décadas de 1970 e 1980, o Estado recuperou iniciativas de programas compensatórios alimentares, socioeconômicos e culturais ligados a órgãos e instituições de assistência social atuantes na década de $1940 .{ }^{10}$ Assim, à escola ampliada ao mundo popular corresponde um modelo que oferta o "mínimo" por longas décadas e, quando abre a possibilidade de a maioria da população ficar mais tempo na escola, o Estado confere um conjunto de diretrizes e práticas que desvirtua o sentido que se espera da socialização escolar, qual seja: dispor o acesso a conhecimentos e habilidades que permitam a construção do sujeito e, no caso brasileiro, especialmente com a Constituição de 1988, sujeito cidadão de direitos capaz de atuar na consolidação da nossa democracia.

Contudo, não é essa a tônica que se vai dar na década de 1990, pois, como sustenta Peregrino (2010, p. 93), a narrativa da política educacional dos "dois mandatos de Fernando Henrique Cardoso (1994-2002) guarda continuidades em relação às políticas anteriores". Na verdade, continua com a "tendência apontada ao final da ditadura militar, a de realizar, na expansão da escola pública para os grupos antes excluídos, a modificação do perfil institucional da escola, especialmente daquela de nível fundamental". Esse processo, como se disse, gera perda da dimensão "escolar" concomitantemente à ampliação da dimensão "assistencial".

De modo sistematizado, pode-se dizer que o processo de marginalização dos grupos populares perante os ganhos da socialização escolar - em especial o

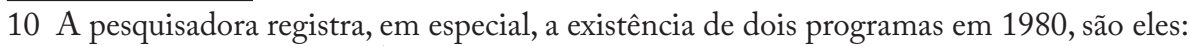
Programa Nacional de Ações Socioeducativas e Culturais para Populações Carentes Urbanas (PRODASEC/Ủrbano) e o Programa Nacional de Ações Socioeducativas e Culturais para Populações Carentes Rurais (PRODASEC/Rural). 
da integração pela aquisição de conhecimentos e habilidades comuns - vai encontrar um importante reforço no período da ditadura militar, já que a incorporação desses grupos aos sistemas escolares foi marcada pela introjeção de políticas sociais na escola. Isso resultou em perda das funções eminentemente escolares. Isto é, na medida em que o mundo popular adentra a escola, ocorre um processo denominado de "desescolarização da escola" (Peregrino, 2010, p. 99), que consiste em um fenômeno de adaptação da escola a novas funções, as quais estão relacionadas à gestão de políticas sociais.

A década de 1990 também é emblemática, segundo Algebaile (2009). Para a autora, as mudanças institucionais da escola nessa década decorrem da vinculação entre programas de renda mínima e escolarização. Nesse sentido, à semelhança das políticas de focalização via escola realizadas no regime militar, o uso instrumental da escola para realizar a aplicação de programas compensatórios em âmbito nacional, muito em virtude das vantagens operacionais - por exemplo, cadastramento de beneficiários e controle de frequência escolar -, ocorre naturalmente.

A respeito dessa arquitetura repassada à burocracia educacional para a implementação de programas, que nos diz também de um repasse da responsabilização do governo federal para o município e deste para as escolas, como que em um jogo de pega e repassa, Algebaile (2009, p. 317) diz o seguinte:

$\mathrm{Na}$ maioria dos municípios, a infraestrutura material e de pessoal das secretarias de educação tornou-se a principal base de operação do programa. Delas saíram as salas e o mobiliário que emergencialmente serviriam de suporte ao trabalho das equipes e à guarda de material. Delas também veio a maioria dos profissionais temporários e permanentes: componentes de equipes pedagógicas foram deslocados para coordenar as novas tarefas; escolas se tornaram postos de cadastramento; professores, funcionários administrativos e funcionários de apoio das escolas foram emprestados para realizá-lo.

Como fica claro na citação apresentada, um conjunto de atividades administrativas encharcou a área educacional com finalidades estranhas às diretrizes de seu mundo. Os governos municipais subordinaram as equipes pedagógicas e a burocracia escolar ao programa social; por sua vez, essas ações despotencializaram a atuação da escola em suas demandas e necessidades e a fragilizou. Um exemplo concreto dessa fragilidade é a improvisação das práticas de gestão em parte significativa das instituições escolares.

Então, a escola tornou-se um lugar de disputa entre a escolarização e a política pública não escolar. Capturada como meio estratégico para a resolução de problemas referidos aos programas assistenciais, a escola tem seu trabalho de socializar conhecimentos completamente prejudicado, e isso, de certa maneira, revela uma regularidade no retardamento da integração e da equidade social no nosso país, pois o Estado brasileiro simplesmente desconfigura o clássico trabalhado de escolarização em nível institucional, sendo seus efeitos um processo de marginalização por dentro, ou seja, a oferta de uma "escola pobre para os pobres" (Algebaile, 2009). 
A esse movimento acrescenta-se um processo de precarização das unidades escolares nas dimensões do espaço físico, nas condições de trabalho e, até mesmo, na formação de pessoal. Há, portanto, uma convergência das práticas de marginalização que, no contexto democrático, pouco fortalece os membros de uma sociedade imbuídos da capacidade de agir individual e coletivamente. A fragilização da escola remete a fracassos cujos efeitos se está a sentir, entre os quais a inserção frágil dos indivíduos e da classe popular na esfera pública, mas também no mundo do trabalho.

Para Cavaliere (2009), esse quadro assume caracterizações de uma escola minimalista, que diz respeito às dificuldades com as quais as instituições escolares lidam diariamente, como a falta de espaço, de material, de profissionais e de condições adequadas para a equipe pedagógica e seus alunos. A autora também aponta o uso da estrutura escolar pelo Estado em sua tarefa de ofertar políticas sociais. Um dos motivos para que isso ocorra, de acordo com Cavaliere, é o mérito de a escola ser a principal instituição com maior presença em todo o território nacional.

A despeito de todas as críticas, pertinentes ou não, a importância da escola para a sociedade brasileira fica evidente quando se observa que quase todos os programas sociais desenvolvidos por diferentes governos, muitos dos quais vieram a se fundir no atual Programa Bolsa Família, passam por ela. Isso por que sua capilaridade é única entre todas as demais instituições, públicas ou particulares. Mesmo as organizações de comunicação de massa, principalmente cadeias de televisão e rádio, e algumas organizações religiosas, que têm grande alcance em todo o País, não estabelecem com a população a relação orgânica, pessoal e duradoura, tal como o faz a escola. Num país de imenso território, como o Brasil, o Estado se faz presente por meio dela de maneira mais eficaz. (Cavaliere, 2009, p. 56)

Com efeito, ao atuar via escola, o Estado parece não reconhecer os limites dessa instituição para realizar determinadas tarefas e torna o trabalho de socialização ainda mais desafiador. Além de administrar demandas de outros setores da burocracia estatal, a escola precisa resolver uma série de questões muitas vezes acompanhadas de tensões: um exemplo é dialogar com outras culturas. Ora, interagir com os estudantes é uma missão enorme, sobretudo quando considerado o fato de que eles pertencem à outra forma socializadora (Thin, 2006). O que o processo de universalização da formação escolar colocou em questão, entre outras coisas, foi o contato entre a cultura escolar e a cultura popular. A interação entre elas ainda depende de motivações e expectativas recíprocas.

Desse modo, pode-se afirmar que a fragilidade pela qual passou a instituição escolar se revela mais assustadoramente perigosa na possibilidade de a escola não conseguir criar pontes com o seu público. Cavaliere (2009) também chama atenção para esse ponto ao dizer que o desencontro entre a escola pública e a classe popular existe, porque são dois processos de socialização distintos: 
As formas de socialização das classes populares ainda contam com o trabalho juvenil em diversas modalidades e, ao lado dele, com um tipo de formação que induz muito cedo o adolescente e o jovem à autonomia. A tutela, típica da ação escolar, é algo que incomoda particularmente ao jovem de classe popular, que, em geral, adquire mais cedo sua independência de locomoção e autocuidados. A escola, empobrecida e burocratizada, que tutela, mas não oferece algo desafiador, acaba sendo intolerável para uma parte desses jovens, perdendo-os para outros chamamentos da vida cotidiana. (Cavaliere, 2009, p. 57)

Uma das ações mais desafiadoras colocadas à escola é a construção do diálogo com o estudante e seu responsável pedagógico, tarefa que envolve considerar os valores da cultura popular. Como bem lembra Cavaliere (2009), a independência é um dos elementos formador do comportamento do jovem de classe popular. Esse aspecto cultural é constituído pela trajetória que, muitas vezes, traz a inserção precocemente no mercado de trabalho e outros impulsos de sua condição social. Nesse sentido, é um grande desafio para a escola estabelecer diálogo, uma vez que seus elementos culturais são comandos que tutelam aqueles que chegam até ela. Será que aos jovens de classe popular não chegaram os benefícios dessa tutela? O mais importante nesse momento é evitar a assimetria da relação, pois limita os alcances pedagógicos, gera a inadaptabilidade do estudante, sua evasão e, no extremo, promove mais desigualdades sociais.

Mas vale dizer que essa questão não é uma realidade apenas do Brasil. É um desafio das escolas massificadas. Nas escolas públicas portuguesas, a "cultura oficial"é marcadamente "urbana, letrada, teoricista, abstratizante, de classe média, adultocêntrica, androcêntrica, lusa e católica" ${ }^{11}$ (Silva, 2003, p. 356), ao passo que a cultura periférica se refere à diversidade local, grupos quase sempre vistos com hábitos e valores alheios à cultura escolar. Desse modo, a cultura escolar estaria mais em conformidade com a cultura de alunos e famílias provenientes de meios com as características valorizadas pela instituição e, em relação à cultura de alunos oriundos de meios populares, o que prevalece são algumas tensões. Nessa discussão, a própria relação entre a escola e a família é essencialmente uma relação entre culturas. Para Silva (2003, p. 356), a relação entre culturas pode apresentar duas formas de desfecho no espaço escolar: uma de confronto, quando há baixa comunicação entre cultura escolar e cultura dos alunos, e outra de conflito ou choque cultural, quando a descontinuidade entre as culturas é total.

No caso das escolas brasileiras, é preciso relativizar a força dessa cultura escolar, pois a entrada dos pobres em seu recinto foi acompanhada por um processo de precariedade institucional que interfere na forma dela se impor dentro de seus muros. Além disso, diferentemente das escolas portuguesas, nas quais o multiculturalismo está muito presente, os outros das nossas escolas são os alunos das classes mais empobrecidas, no caso dos grandes centros urbanos, são os pobres das favelas e periferias.

11 Essa cultura oficial referida por Silva (2003) simboliza uma dificuldade de aproximação com as culturas dos alunos. Para entender a reflexão de Silva sobre interculturalidade, ver o capítulo seis. 
O fato é que a cultura periférica passa por um processo de diminuição quando entra em contato com a cultura escolar. Não é nenhuma surpresa encontrar situações em que professores e gestores desqualificam o modo como a família popular educa seus filhos, como se vestem ou mesmo como convivem, e geralmente essas falas estão associadas a alguma observação referida ao lugar de moradia. Um exemplo: ao entrevistar professores que lidam com alunos moradores de favelas cariocas, Telles (2009) ressalta que boa parte dos entrevistados considera a família nuclear o modelo de família estruturada e, quando esses professores se deparam com famílias de formato fugidio do padrão conhecido por eles, a reação é a de que elas são um tormento para o projeto da escola. E, em relação ao estudante, Telles (2009) mostra que boa parte dos professores ouvidos na pesquisa atribui a dificuldade no processo de ensino-aprendizagem à baixa motivação e ao baixo valor à escola conferido por esse aluno. Nas conclusões de sua pesquisa, Telles (2009) enfatiza que a fala de desqualificação do estudante, além de estar carregada de preconceitos que são fortalecidos por um distanciamento do professor em relação ao universo do aluno, transfere a responsabilidade do sucesso/fracasso escolar para o aprendiz.

É claro que essas falas refletem também a histórica marginalização da classe popular no processo de redefinição dos espaços da cidade do Rio de Janeiro, o que marca a sua experiência com diversas instituições. Mas é na escola que os aspectos negativos da ecologia do lugar de moradia dos alunos e de suas famílias tornam-se fatores relevantes para o curso da vida. A escola tem que cuidar para não deixar predominar percepções que de alguma maneira estabelecem um estrutural distanciamento dos profissionais em relação ao público que atendem.

\section{CONSIDERAÇÕES FINAIS}

A realidade brasileira também tornou a escola uma instituição central na vida de suas crianças e adolescentes. É verdade que os desafios colocados à escola variam e apresentam níveis diferentes de complexidades. Como também é verdade que a responsabilidade geralmente recai apenas sobre os profissionais da escola. Mas é dever do Estado planejar ações que tornem o desafio de escolarização uma atividade menos solitária. Outro ator fundamental na tarefa de contribuir com a socialização escolar é a família, que, embora seja o mais fragilizado em recursos, tem potencial de garantir ao menos a frequência à escola.

O Estado, por meio de políticas públicas, e a escola, com ações oriundas de seus profissionais, podem tornar-se guardiãs de uma cultura escolar brasileira que tenha compromisso com o aprendizado equitativo dos estudantes. Para tanto, é importante que se perguntem quanto as ações escolares têm sido seletivas, ou seja, produtoras e reprodutoras de exclusões e da desigualdade social. Nessa tarefa, o papel da secretaria de educação é crucial, salvaguardando tomadas de decisão que deem mais condições de educabilidade (López, 2005).

A educabilidade é uma noção que ajuda a pensar o grau de aproximação entre a escola e seus alunos. Os alunos possuem diferentes características (individuais e sociais) que os colocam em posições também diferentes no processo de aprendizagem dos conteúdos escolares. Nesse sentido, o desafio da escola é saber 
dialogar com um público que apresenta diferentes caminhos de chegada à escola. Uma pergunta, então, se impõe: Como tratar os alunos de maneira que a capacidade deles de "jogar o jogo" da aprendizagem seja valorizada? A solução não é tão simples, mas certamente uma secretaria atenta aos desafios atuais provavelmente se fará esse questionamento, o que pode desencadear ações mais efetivas.

Subsidiada por uma secretaria assim orientada, a escola poderá assumir o compromisso de agir para diminuir a distância do seu aluno real. Essa distância de que se fala pode ser qualificada pela baixa abertura da escola em se comunicar com o estudante. Muitas vezes a escola tem dificuldade de saber o perfil do seu aluno, como também está desprevenida para o que acontece em espaços-tempos escolares importantes. $\mathrm{O}$ recreio é um exemplo disso. $\mathrm{O}$ espaço-tempo do recreio aparece como um momento em que as escolas utilizam critérios pouco institucionalizados. $\mathrm{E}$ isso dá margem para a existência de diferentes modos de autoridade e de comunicação, por meio dos quais se pode identificar certa desqualificação do aluno como sujeito portador de direitos.

Em uma realidade de baixa abertura escolar é mais provável a difusão de senso comum, que traz "verdades indiscutíveis", como a falta de compromisso do aluno e de sua família pelas questões escolares (Rossi e Burgos, 2014). Mas, mesmo que haja algumas evidências que sustentem esse argumento da falta de compromisso, a família popular tem forte interesse por mais escola na vida de seus filhos. A questão, então, é tentar entender "por que as escolas, ainda que em diferentes graus, seguem se mostrando pouco confiante na possibilidade de mobilizar as famílias" (Burgos, 2012, p. 1.045).

Burgos (2012) entende que essa condição escolar pode ter alguma relação com a cultura autoritária que foi predominante no regime militar. Essa cultura não deixa de pautar o processo de ampliação da escola, tendo implicações no cotidiano dessa instituição. E por esse motivo a escola "tem muita resistência em lidar com seu público segundo um padrão de igualdade e de equidade". Certamente, esse tipo de cultura compromete a abertura da escola para o envolvimento do aluno e também de sua família, em um processo que pode ajudá-lo a reconhecer suas próprias capacidades.

A tarefa a que se dispôs este artigo foi uma tentativa de responder às questões colocadas em seu início. Com base nos textos mobilizados, é possível argumentar que o sentido e a realização da escola para os pobres têm se dado com o incremento de políticas sociais que se apropriaram da instituição escolar (Algebaile, 2009), e isso fragilizou o que é eminentemente de sua natureza: desenvolver a socialização escolar. $\mathrm{E}$, nesse quadro mais geral de "escola minimalista" (Cavaliere, 2009), cuja afirmação se deu também no contexto de "massificação autoritária" (Burgos, 2012), o que está em jogo é a redefinição da relação da escola com o seu público, de modo específico entre os profissionais da escola e seus alunos. Redefinir relações com seus estudantes parece ser um grande desafio à instituição escolar, mas a criação de um ambiente que favoreça o desenvolvimento de conhecimentos e habilidades educacionais depende disso.

De certo modo, a dificuldade de construir uma socialização escolar equitativa no Brasil pode estar ancorada nos limites delimitados pelo distanciamento da escola com os estudantes populares. A questão é que não podemos perder de vista 
a capacidade da instituição escolar de alimentar uma interação com seu público a fim de tornar a experiência do mundo popular um potencial elemento para a socialização escolar. Vale ressaltar que essa aproximação não é apenas uma estratégia pedagógica, mas uma forma de construir um ambiente no qual o estudante seja recebido como um sujeito de direito (Burgos, 2014), capaz de fortalecer os valores democráticos. Então, trata-se de uma cultura escolar que firma o pacto democrático com os jovens da classe popular nas interações específicas, entre os atores da escola: gestores, professores, alunos e seus responsáveis pedagógicos.

\section{REFERÊNCIAS}

Algebaile, E. Escola pública e pobreza no Brasil: a ampliação para menos. Rio de Janeiro: Lamparina; FAPERJ, 2009.

Azevedo, F. Manifesto dos Pioneiros da Educação Nova. A reconstrução educacional do Brasil: ao povo e ao governo. Rio de Janeiro, 1932.

. Manifesto dos educadores: mais uma vez convocados. Brasília: Ministério da Educação, 2010.

Bourdieu, P. Contrafogos: táticas para enfrentar a invasão neoliberal. Rio de Janeiro: Jorge Zahar, 1998.

Brasil. Constituição (1934). Constituição da República dos Estados Unidos do Brasil de 1934: promulgada em 16 de julho de 1934. Diário Oficial da União, Rio de Janeiro: Presidência da República, 16 jul. 1934. Disponível em: <http://www.planalto.gov.br/ ccivil_03/constituicao/constituicao34.htm>. Acesso em: 15 nov. 2017.

. Constituição (1937). Constituição da República dos Estados Unidos do Brasil de 1937: promulgada em 10 de novembro de 1934. Diário Oficial da União, Rio de Janeiro: Presidência da República, 10 nov. 1937. Disponível em: <http://www.planalto. gov.br/ccivil_03/constituicao/constituicao37.htm>. Acesso em: 15 nov. 2017.

. Constituição (1946). Constituição da República dos Estados Unidos do Brasil de 1946: promulgada em 18 de setembro de 1946. Diário Oficial da União, Rio de Janeiro: Presidência da República, 19 set. 1946. Disponível em: <http://www.planalto.gov.br/ ccivil_03/constituicao/constituicao46.htm>. Acesso em: 15 nov. 2017.

. Decreto-lei n. 8.530, de 2 de janeiro de 1946. Dispõe sobre a finalidade e organização do Ensino Normal. Diário Oficial da União, 4 jan. 1946. Seção 1, p. 116. Disponível em: http://www2.camara.leg.br/legin/fed/declei/1940-1949/decreto-lei8530-2-janeiro-1946-458443-publicacaooriginal-1-pe.html>.Acesso em: 14 nov. 2017.

.Lei n. 4.024, de 20 de dezembro de 1961. Fixa as Diretrizes e Bases da Educação Nacional. Diário Oficial da União, Brasília, 20 dez. 1961. Disponível em: <http://www. planalto.gov.br/ccivil_03/leis/L4024.htm>. Acesso em: 15 nov. 2017.

Lei n. 5.540, de 28 de novembro de 1968. Fixa normas de organização e funcionamento do ensino superior e sua articulação com a escola média, e dá outras providências. Diário Oficial da União, Brasília, 28 nov. 1968. Disponível em: <http:// www.planalto.gov.br/ccivil_03/Leis/L5540.htm>.Acesso em: 15 nov. 2017. 
Brasil. Lei n.5.692, de 11 de agosto de 1971. Fixa Diretrizes e Bases para o ensino de $1^{\circ} \mathrm{e}$ $2^{\circ}$ graus, e dá outras providências. Diário Oficial da União, Brasilia, 12 ago.1971. Disponível em: <http://www.planalto.gov.br/ccivil_03/LEIS/L5692.htm>. Acesso em:15 nov. 2017.

. Constituição (1988). Constituição da República Federativa do Brasil de 1988: promulgada em 5 de outubro de 1988. Diário Oficial da União, Brasília: Presidência da República, 5 out. 1988. Disponível em: <http://www.planalto.gov.br/ccivil_03/ constituicao/constituicaocompilado.htm>. Acesso em: 15 nov. 2017.

. Lei n. 9.394, de 20 de dezembro de 1996. Estabelece as Diretrizes e bases da Educação Nacional. Diário Oficial da União, Brasília, 23 dez. 1996. Disponível em: <http://www.planalto.gov.br/ccivil_03/leis/L9394.htm>. Acesso em: 15 nov. 2017.

Burgos, M. Escola pública e segmentos populares em um contexto de construção institucional da democracia. DADOS - Revista Ciências Sociais, Rio de Janeiro: UERJ, v. 54, n. 4, p. 1.015-1.054, 2012. Disponível em: <http:/www.scielo.br/pdf/dados/ v55n4/v55n4a06.pdf >. Acesso em: 4 nov. 2017.

. (Org.). A escola e o mundo do aluno - estudos sobre a construção social do aluno e o papel institucional da escola. Rio de Janeiro: Garamond, 2014.

Cavaliere, A. M. Escolas de tempo integral versus alunos em tempo integral. Em Aberto, Brasília: INEP,v. 22, n. 80, p. 51-63, 2009. Disponível em: <emaberto.inep.gov.br/index. php/emaberto/article/download/2220/2187>. Acesso em: 1 nov. 2017.

DaMatta, R. Carnavais, malandros e heróis: para uma sociologia do dilema brasileiro. 7. ed. Rio de Janeiro: Editora Rocco, 1997.

IBGE - Instituto Brasileiro de Geografia e Estatística. Pesquisa Nacional por Amostra de Domicílios 1992-2007. Rio de Janeiro: IBGE, 1992-2007.

López, N. Equidad educativa y desigualdad social: desafios de la educación en le nuevo escenario latinoamericano. Buenos Aires: Instituto Internacional de Planeamiento de la Educación; UNESCO, 2005.

Nóvoa, A.; Schriewer, J. (Orgs.). A difusão mundial da escola: alunos, professores, currículo, pedagogia. Lisboa: Educa, 2000.

Peregrino, M. Trajetórias desiguais: um estudo sobre os processos de escolarização pública de jovens pobres. Rio de Janeiro: Garamond, 2010.

Romanelli, O. História da educação no Brasil: (1930/1973). 4. ed. Petrópolis: Vozes, 1984. Rossı, L.; Burgos, M. O valor da educação escolar para as famílias: confronto entre a percepção dos responsáveis e o senso comum escolar. In: Burgos, M. (Org.). A escola e o mundo do aluno: estudos sobre a construção social do aluno e o papel institucional da escola. Rio de Janeiro: Garamond, 2014. p. 50-71.

Saviani, D. Pedagogia histórico-crítica: primeiras aproximações. 2. ed. São Paulo: Cortez; Autores Associados, 1991.

. O legado educacional do século XX no Brasil. Campinas: Autores Associados, 2004.

Silva, P. Escola-família, uma relação armadilhada: interculturalidade e relações de poder. Porto: Edições Afrontamento, 2003. 
Schwartzman, S.; Bomeny, H. M. B.; Costa, V. M. R. Tempos de Capanema. 2. ed. Rio de Janeiro: Fundação Getúlio Vargas; Editora Paz e Terra, 2000.

Telles, S. S. Pobreza e desigualdade da escola na favela. In: Paiva, A.; Burgos, M. (Orgs.). A escola e a favela. Rio de Janeiro: Editora Pallas; PUC-Rio, 2009. p.133-171.

THin, D. Para uma análise das relações entre famílias populares e escola: confrontação entre lógicas socializadoras. Revista Brasileira de Educação, Rio de Janeiro: ANPEd; Campinas: Autores Associados, v. 11, n. 32, p. 211-225, maio/ago. 2006. Disponível em: $<$ http://www.scielo.br/pdf/rbedu/v11n32/a02v11n32.pdf >. Acesso em: 20 jun. 2015

\section{SOBRE O AUTOR}

Francicleo Castro Ramos é doutorando em sociologia e antropologia pela Universidade Federal do Rio de Janeiro (UFRJ).

E-mail: francicleocastro@gmail.com 